\title{
LETRAMENTOS ACADÊMICOS NA EDUCAÇÃO BÁSICA: PERSPECTIVAS, PESQUISAS E POSSIBILIDADES
}

\section{ACADEMIC LITERACIES IN BASIC EDUCATION: PERSPECTIVES, RESEARCH AND POSSIBILITIES}

\author{
Jonathan Zotti da Silva ${ }^{1}$ \\ Universidade Federal do Rio Grande do Sul (UFRGS)
}

\begin{abstract}
RESUMO
Os estudos de letramentos acadêmicos se desenvolveram no contexto do ensino superior, principalmente devido às dificuldades de leitura e escrita dos estudantes que chegam à universidade. Este artigo tem o objetivo de discutir os letramentos acadêmicos na educação básica, descrevendo trajetórias e apontando para possibilidades de desenvolvimento do campo. Assim, são trazidas as perspectivas de alguns autores a respeito das práticas de letramento acadêmico no contexto da escola. Depois são apresentados estudos realizados em países da América do Norte e da Europa, que demonstram um campo de estudos bem estabelecido, ao passo que, ao relatar os estudos realizados no Brasil, percebe-se a incipiência do campo. Por fim, são apontadas algumas possibilidades de investigação para desenvolver os estudos de letramentos acadêmicos na educação básica, com destaque para a iniciação científica na escola e para as feiras de ciência.
\end{abstract}

PALAVRAS-CHAVE: Letramentos Acadêmicos; Educação Básica.

\begin{abstract}
Academic literacies studies have been developed in the context of higher education, mainly due to the reading and writing difficulties of students who arrive at university. This paper aims to discuss academic literacies in basic education, describing paths and pointing possibilities for developing the field. This, it introduces the perspectives of some scholars about academic literacy practices in the context of school. After, studies carried out in North America and Europe are reported, showing a well-established field of study, whereas studies conducted in Brazil indicates a incipient field. Finally, some research possibilities are pointed out to develop the academic literacies studies in basic education, with emphasis on school scientific initiation and on science fairs.
\end{abstract}

KEYWORDS: Academic Literacies; Basic Education.

\section{INTRODUÇÃO}

A democratização do acesso ao ensino superior no Brasil no início do século XXI permitiu a entrada de estudantes de origem popular à universidade. Os desafios que esses estudantes enfrentam para se manter estudando no ensino superior tem sido interesse de pesquisa dos estudos de letramentos acadêmicos ${ }^{2}$. Dentre essas dificuldades, estão as práticas sociais de linguagem privilegiadas no contexto universitário, às quais muitas vezes esses estudantes não tiveram acesso na educação básica. Tais dificuldades com as práticas de leitura e escrita

\footnotetext{
${ }^{1}$ Mestrando em Letras pelo Programa de Pós-Graduação em Letras da Universidade Federal do Rio Grande do Sul. Professor de Língua Portuguesa da rede municipal de Canoas (RS). E-mail: jonzsilva@gmail.com

2 Para estudos mais detalhados sobre o assunto, ver o artigo de Fischer e Dionísio (2011), a seção 2.2 da tese de Juchum (2016) e o artigo de Oliveira (2017).
}

Revista do GELNE, Natal/RN, Vol. 21 - Número 1: p. 20-31. 2019 
valorizadas na universidade alimentam o discurso do déficit, que sustenta que os estudantes chegam ao ensino superior sem saber ler e escrever.

Tal discurso foi o que motivou a pesquisa de Fischer (2007), considerada pioneira nos estudos de letramentos acadêmicos no Brasil. A pesquisadora realizou um estudo etnográfico longitudinal com o objetivo de investigar como se dá a constituição letrada de três alunas durante seu primeiro ano da licenciatura em Letras. A contribuição dessa pesquisa para o campo de estudo foi a proposição de um modelo de letramento na esfera acadêmica que não negue as práticas sociais de linguagem vivenciadas na escolarização básica dos estudantes, mas que, a partir delas, negocie novas práticas sociais e identidades propostas pelo meio acadêmico. Nesse sentido, Fischer (2007) aponta o modelo dialógico de letramentos acadêmicos como uma alternativa ao discurso do déficit de letramento, pois a investigação da constituição letrada das estudantes de Letras demonstram que o modelo proporciona "um percurso que se inicia com o discurso do déficit ou da crise do letramento e evolui positivamente para o uso do Discurso reciclado, na direção do uso dos letramentos críticos” (p. 250).

Assim como na pesquisa de Fischer (2007), o modelo de Letramentos Acadêmicos ${ }^{3}$ proposto por Lea e Street $(1998 ; 2006)$ tornou-se referência no estudo das práticas letradas no contexto universitário. Os autores sustentam que as abordagens da escrita no ensino superior dividem-se em três modelos de letramento. O modelo de babilidades de estudo (study skills) que enxerga o letramento como um conjunto de habilidades universais que pode ser transferidos de um contexto para outro. Para os autores, "o foco [dessa abordagem] está nas tentativas de consertar problemas com a aprendizagem do estudante, que são tratados como uma espécie de patologia"4 (LEA; STREET, 1998, p. 158). É nesse modelo que se sustenta o discurso do déficit.

Um pouco mais sensível ao contexto do estudante e da escrita, o segundo modelo chamase socialização acadêmica (academic socialization). Nessa perspectiva, os estudantes devem ser inseridos em uma nova cultura, a cultura acadêmica. A crítica dos autores se dá pelo fato de que essa abordagem "parece entender que a academia é uma cultura relativamente homogênea, cujas normas e práticas devem simplesmente ser aprendidas para prover acesso ao todo da instituição" (LEA; STREET, 1998, p. 158). Assim, esse modelo ignora as nuances sobre o que conta como escrita acadêmica nas diversas áreas do conhecimento.

Por fim, Lea e Street (1998) descrevem o modelo de Letramentos Acadêmicos (academic literacies). Esse modelo busca compreender as produções de sentido e os aspectos culturais e identitários relacionados a tais práticas ao invés de tratar os usos da leitura e da escrita apenas como habilidades e deficiências (LEA; STREET; 1998). Nessa perspectiva, uma característica dominante das práticas de letramento acadêmico é "a exigência de mudar práticas entre um contexto e outro, de desenvolver um repertório de práticas linguísticas apropriadas para cada contexto e de lidar com os significados e identidades sociais que [cada contexto] evoca" (p. 159).

Nesse âmbito este artigo tem o objetivo de discutir os letramentos acadêmicos na educação básica, descrevendo trajetórias e apontando para possibilidades de desenvolvimento do campo. Para isso, foram elaboradas as seguintes perguntas de discussão teórica:

I - Quais são as perspectivas sobre letramentos acadêmicos na educação básica?

II - Quais são as pesquisas já desenvolvidas que investigaram os letramentos acadêmicos na escola?

\footnotetext{
${ }^{3}$ Neste artigo "letramentos acadêmicos", grafado com letras iniciais minúsculas, refere-se ao conjunto de práticas de leitura e escrita na academia, ao passo que "Letramentos Acadêmicos" aponta para a abordagem da escrita acadêmica proposto por Lea e Street (1998; 2006).

4 The focus is on attempts to 'fix' problems with student learning, which are treated as a kind of pathology.

${ }^{5}$ It appears to assume that the academy is a relatively homogeneous culture, whose norms and practices have simply to be learnt to provide access to the whole institution.

6 The requirement to switch practices between one setting and another, to deploy a repertoire of linguistic practices appropriate to each setting, and to handle the social meanings and identities that each evokes.
}

Revista do GELNE, Natal/RN, Vol. 21 - Número 1: p. 20-31. 2019 
III - Quais são as possibilidades para desenvolver os estudos de letramentos acadêmicos na educação básica?

Sendo assim, este artigo está dividido em três seções: na primeira apresento as perspectivas de diversos autores a respeito dos letramentos acadêmicos no contexto de educação básica, discutindo se a escola pode desenvolver práticas acadêmicas. $\mathrm{Na}$ segunda seção, reviso estudos de letramentos acadêmicos no contexto escolar em outros países e no Brasil, descrevendo os focos de interesse desses estudos. Na terceira e última seção, proponho objetos de pesquisa para os estudos de letramentos acadêmicos na educação básica.

\section{Perspectivas sobre letramentos acadêmicos na educação básica}

Os letramentos acadêmicos se desenvolveram na investigação das práticas sociais de leitura e escrita no contexto de ensino superior, especialmente no Brasil. No entanto, a educação básica também pode ser foco dos estudos na área. Mary Lea e Brian Street (2006), pesquisadores que popularizaram a perspectiva dos Letramentos Acadêmicos, propõem que, "embora o termo 'letramentos acadêmicos' tenha sido originalmente desenvolvido no que diz respeito ao estudo dos letramentos no ensino superior e na universidade, o conceito também se aplica da educação infantil ao ensino médio" (p.368). De forma breve, as práticas de letramento acadêmico podem ser definidas como as práticas que envolvem "leitura e escrita nas disciplinas" (LEA; STREET, 1998, p. 157, tradução minha ${ }^{8}$ ). Tais práticas são comuns, mas não exclusivas do contexto universitário. Se os estudantes das etapas da educação básica aprendem os assuntos através da leitura e escrita de textos de determinada área, então eles se engajam em práticas de letramento acadêmico.

Apesar de tal apontamento, estudiosos brasileiros, de maneira geral, preferem utilizar o conceito de letramento acadêmico apenas para o ensino superior. Fiad (2011) reconhece que há práticas de letramento que perpassam todos os níveis de escolarização, mas considera que o letramento acadêmico é específico à esfera da universidade. Nesse mesmo sentido, Marinho (2010) argumenta que a leitura e escrita de gêneros acadêmicos de referência como artigos, teses, monografias, dissertações, resenhas acadêmicas, entre outros, não costumam fazer parte das práticas de leitura e escrita nos cursos de ensino fundamental e ensino médio.

A partir de uma discussão sobre as fronteiras entre os letramentos acadêmico, científico e escolar, Barros (2017) defende que o termo letramento acadêmico tem a ver com a especificidade das práticas sociais de leitura e escrita na universidade enquanto que o conceito de letramento escolar daria conta da especificidade dessas práticas na escola, sustentando que seria reducionismo igualar os dois termos. Barros (2017) ainda reconhece que existem práticas de letramento que envolvem gêneros acadêmicos no contexto escolar, mas tais práticas ocorreriam com o intuito de os alunos se familiarizarem com esses gêneros antes de ingressar na universidade; por isso, afirma que "esses alunos não vivenciam ainda as práticas acadêmicas enquanto práticas sociais desenvolvidas em contextos universitários, mas tendem a ser meio que preparados para o contexto no qual irão ingressar" (p. 64). Além dessa prática, o pesquisador salienta que uma necessidade real de fazer uso de gêneros acadêmicos tanto na universidade quanto na escola "parece ser o de produzir conhecimento enquanto prática investigativa, o que implica, de certo modo, o desenvolvimento do letramento científico" (BARROS, 2017, p. 64), e não o desenvolvimento de letramento acadêmico.

Fischer (2007), em sua tese, apresentou um ponto de vista distinto dos entendimentos relatados nos estudos acima, afirmando que a denominação letramento acadêmico é "perfeitamente plausível a outros contextos, que envolvam ambientes e práticas formais de

\footnotetext{
7 Although the term academic literacies was originally developed with regard to the study of literacies in higher education and the university, the concept also applies to K-12 education.

8 Reading and writing within disciplines.
} 
escolarização (Ensino Fundamental, Ensino Médio, Educação de Jovens e Adultos etc.)" (p. 4445). Nessa mesma perspectiva, o professor e pesquisador português Carvalho (2013; 2015) propõe que o letramento acadêmico seja desenvolvido de forma contínua desde a escola até a universidade. No entanto, para que isso seja possível, seria necessário que fosse instituída na educação básica uma abordagem que não apenas reproduza conhecimentos, mas que possa envolver os estudantes em práticas de leitura e escrita "que articulem a construção do conhecimento numa dada área de saber com as linguagens específicas que o estruturam e o veiculam" (CARVALHO, 2015, p. 93).

Em estudo anterior, Carvalho (2014) propõe que o letramento acadêmico seja desenvolvido "numa perspetiva longitudinal, ao longo do percurso escolar do aluno até à universidade, de forma abrangente e pela articulação de dois planos, o da disciplina de língua e o das outras disciplinas escolares" (p. 12). No plano da disciplina de língua, o autor propõe que "os gêneros textuais implicados na aquisição e expressão dos saberes disciplinares deveriam ser objeto de trabalho" (CARVALHO, 2014, p. 12) e, no plano dos outros componentes curriculares, a proposta é realizar tarefas que, "implicando o uso da linguagem, potenciassem uma aquisição e elaboração do conhecimento mais profunda do que a que normalmente resulta das atividades sugeridas nos livros escolares" (CARVALHO, 2014, p. 12).

Assim, concordam com Lea e Street (2006) as perspectivas de Fischer (2007), que considera que usos acadêmicos da leitura e escrita podem ser realizados na escola, e de Carvalho (2014, 2015), que propõe que práticas de letramento acadêmico sejam iniciadas na educação básica a fim de que conhecimentos possam ser produzidos pelos alunos ainda nessa etapa da educação formal.

Uma perspectiva brasileira sobre a escrita acadêmica nas diversas áreas do conhecimento pode ser encontrada no livro "Ler e Escrever: compromisso de todas as áreas" (NEVES et al, 2011). O conjunto de textos do livro não se refere especificamente ao termo letramento acadêmico, mas assume que "ensinar a ler e a escrever é tarefa de todas as áreas, um compromisso da escola e não exclusivamente do professor de português" (NEVES et al, 2011, p. 15), e que cada professor deve ter "um conhecimento profundo das características do ler e do escrever na sua área de atuação" (NEVES et al, 2011, p. 15). Tal perspectiva está de acordo com os Letramentos Acadêmicos (LEA; STREET, 1998; 2006) na medida em que considera as particularidades das práticas de leitura e escrita em cada área do conhecimento.

Mais consolidada do que no Brasil, diversas pesquisas na educação básica foram desenvolvidas na área de letramentos acadêmicos em países norte-americanos e europeus. Uma possível razão para isso é o lugar legitimado que a escrita acadêmica ocupa nesses países desde a educação básica até o ensino superior, materializada especialmente no gênero discursivo ensaio (SCOLLON; SCOLLON, 1981; RUSSEL et al., 2009). Nesse sentido, Crosby (2007) argumenta que estudantes imigrantes que estudaram em escolas estadunidenses compreendem melhor processos de escrita valorizados no ensino superior, pois

a experiência nas escolas de educação básica dos Estados Unidos dá a esses estudantes a
oportunidade de desenvolver seus letramentos acadêmicos ao desenvolver uma
familiaridade com a abordagem de processo de escrita e com a organização do ensaio
acadêmico, conhecido também como ensaio de cinco parágrafos. (p. 49, tradução
minha $^{9}$ )

Por outro lado, no contexto brasileiro, o gênero mais tradicional na educação básica parece ser o gênero redação escolar (PIETRI, 2007), que, não sendo um gênero acadêmico, não

\footnotetext{
9 Experience in U.S. K-12 schools also provides these students with the opportunity to develop their academic literacies by developing a familiarity with the writing process approach and academic essay organization otherwise known as the five paragraph essay. This provides them with some level of knowledge and familiarity with the writing system in English which is a key concept of writing at the college level.
} 
circula no ensino superior. Assim, apesar de ser bem documentado em diversos contextos culturais que as práticas de letramento da escola e da universidade possuem diferenças, no Brasil as fronteiras entre as instituições aparentam ser mais definidas no que se refere às práticas de letramento acadêmico. Consequentemente é compreensível que haja resistência de autores brasileiros em utilizar o termo letramento acadêmico na educação básica.

Assim, na próxima seção deste artigo, apresento algumas pesquisas que investigaram e propuseram práticas de letramento acadêmico na educação básica. Relato inicialmente estudos realizados em outros países, mostrando um percurso bem estabelecido, principalmente nos países da América do Norte e da Europa, e, então, apresento os estudos realizados no Brasil, evidenciando a incipiência do campo em nosso país.

\section{Pesquisas sobre letramentos acadêmicos na educação básica}

De forma semelhante ao desenvolvimento dos estudos de letramento acadêmico no ensino superior, na educação básica o campo também se desenvolveu na investigação das práticas de letramento de estudantes de origem popular, mais especificamente de estudantes imigrantes e de falantes de minorias linguísticas nas escolas de high school. Nesse sentido, a pesquisa desenvolvida por Harklau (2001) se tornou referência, pois consistiu em um estudo longitudinal que acompanhou quatro mulheres falantes de minorias linguísticas na transição entre o último semestre de high school e o primeiro de college ${ }^{10}$, em duas universidades diferentes.

Contrariando pressupostos de teorias cognitivas que propõem que a dificuldade da transição entre o ensino médio e o ensino superior se dá no nível de complexidade das demandas de letramento, a pesquisadora, a partir da natureza social das práticas de letramento proposta pelos Novos Estudos de Letramento (BARTON; HAMILTON, 1998; LEA; STREET; 1998), mostrou que os significados de usos "bons" ou "ruins" de leitura e escrita variam contextual e culturalmente. Além disso, "essa análise enquanto prática social mostra que as percepções das estudantes sobre o que era fácil ou difícil estavam intrinsecamente ligadas às experiências de letramento do ensino médio" (HARKLAU, 2001, p. 51, tradução minha ${ }^{11}$ ). Esse entendimento afasta a pressuposição de que as práticas de letramento que ocorrem na universidade são "superiores" ou "melhores" do que as que ocorrem na escola e esclarece que qualquer julgamento de valor de uma determinada prática ocorre em relação a outra já conhecida. Assim, Harklau percebeu semelhanças e diferenças entre os contextos escolar e universitário:

\footnotetext{
Apesar de considerarem que algumas demandas, como a tomada de notas, serem maiores na faculdade do que no ensino médio, as estudantes acharam bastante semelhante o formato dos livros didáticos e dos testes de múltipla escolha do ensino secundário e do ensino superior, e elas consideraram que o currículo e os critérios de avaliação das aulas da faculdade eram mais fáceis de decifrar do que no ensino médio. Apesar de que a escrita de ensaios seja uma parte integrante do currículo secundário, muito da escrita que essas estudantes encontraram nas primeiras aulas do ensino superior estavam apenas relacionadas à remediação ${ }^{12}$. (p. 51, tradução minha ${ }^{13}$ )
}

\footnotetext{
${ }_{10}$ Neste artigo utilizo termos como "ensino médio" ou "ensino secundário" para me referir a bigh school, e "ensino superior", "universidade" ou "faculdade" para me referir a college.

11 This social-practice analysis shows that students' perceptions of what was easy or difficult were inextricably grounded in their high school literacy experiences.

12 No contexto da pesquisa, práticas leitura e escrita com foco em questões gramaticais de Inglês para Falantes de Outras Línguas (ESOL, na sigla em inglês).

13 Although students found some demands, such as note taking, to be greater in college than in high school, they found the format of high school and college textbooks and multiple-choice tests quite similar, and they actually found the curriculum and evaluative criteria of college classes easier to decipher than high school. Although essay writing was an integral part of their high school curriculum, most of the writing these students encountered in their first college classes was associated only with remediation.
}

Revista do GELNE, Natal/RN, Vol. 21 - Número 1: p. 20-31. 2019 
Outras diferenças apontadas pela pesquisa de Harklau (2001) estão relacionadas com a organização do tempo de aula e com o papel de professor e aluno na responsabilidade pela aprendizagem. Enquanto que "a vasta maioria das atividades de letramento acadêmico nas aulas dessas estudantes aconteciam no tempo de aula” (HARKLAU, 2011, p. 52-53, tradução minha ${ }^{14}$ ), no ensino superior o tempo de aula era visto como uma maneira compacta de entregar informações, "com a pressuposição de que a maioria das atividades letradas das estudantes aconteceriam fora da sala de aula de modo que elas processariam a informação e as leituras da aula no seu tempo e no seu modo" (HARKLAU, 2011, p. 54, tradução minha ${ }^{15}$ ).

Como contribuição aos estudos de letramentos acadêmicos, a pesquisa de Harklau (2001) mostrou que, no contexto estadunidense, existem práticas de letramento acadêmico que ocorrem na escola e permanecem na universidade e outras práticas que surgem no contexto do ensino superior. A mudança mais evidente reside no fato de que a responsabilidade pela aprendizagem na universidade é quase exclusiva do estudante, papel esse que no ensino médio era compartilhado pelos professores. Numa perspectiva de prática social, as práticas letradas que ocorrem no ensino médio constituem um próprio ecossistema, pois, não sendo uma versão mais fraca ou menos desenvolvida do currículo do ensino superior, tais práticas eram sensíveis aos propósitos dessa etapa de ensino (HARKLAU, 2001).

Estudos demonstram que os primeiros usos de escrita e leitura de textos acadêmicos podem começar nas primeiras etapas da educação básica. Oliver (2005) observou como crianças estudantes dos anos finais do ensino fundamental de uma escola internacional na Holanda utilizavam fontes de informação nos seus projetos de pesquisa. Para o pesquisador, "os projetos de pesquisa de crianças podem ser vistos como um encontro inicial com uma composição baseada em fontes, rica em citações e multi-camadas que mais tarde se torna a 'escrita acadêmica" (OLIVER, 2005, p. 369, tradução minha ${ }^{16}$ ). Michael-Luna e Canagarajah (2007) descrevem uma prática pedagógica que apoia a produção textual de estudantes multilíngues do primeiro ano do ensino fundamental. Com base nesse estudo, os autores buscam oferecer a pesquisadores do ensino superior um modelo pedagógico que se baseie no uso combinado das primeira e segunda línguas dos estudantes a fim de enfrentar os desafios da escrita acadêmica na universidade.

O ensino médio, etapa final da educação básica, também é um contexto produtivo para pesquisas sobre letramento acadêmico. Os estudos de caso se configuram como uma metodologia frequentemente utilizada para investigar esse contexto. Nesse sentido, Enright (2011) realizou estudos de casos com três estudantes New Mainstream ${ }^{17}$ durante a execução do projeto final das disciplinas de Inglês e Estudos Sociais. Os achados de sua pesquisa indicam a necessidade de expandir as definições de linguagem acadêmica para melhor compreender a realidade desses estudantes.

Yi (2013) realizou um estudo de caso longitudinal com um adolescente Jogi Yubak $k^{18}$ com o objetivo de investigar sua negociação de múltiplas identidades e seu acesso a práticas de escrita acadêmica durante o curso de dois anos letivos em uma escola de ensino médio americano. Os achados de Yi mostram que o adolescente negociava a identidade de estudante de inglês como segunda língua e de academicamente bem sucedido, o que lhe possibilitava alcançar boas notas,

\footnotetext{
14 The vast majority of academic literacy activities in these students' high school classes took place within classroom time.

15 With the assumption that most of students' literate activity would take place outside the classroom as students processed information from class and readings in their own time and own way.

${ }^{16}$ Children's research projects can be seen as an early encounter with the sourcebased, citation-rich, multi-layered composing which later becomes "academic writing".

17 Termo cunhado pela autora para se referir à grande diversidade e hibridismo de origens socioculturais dos estudantes das salas de aula estadunidenses.

18 Termo coreano que se refere ao fenômeno sul-coreano de enviar crianças e adolescentes em idade escolar para estudar em países anglófonos, especialmente os países norte-americanos (YI, 2013).
} 
mas o impedia de se envolver em grandes demandas de letramento acadêmico devido à sua dificuldade com a língua inglesa (YI, 2013).

Fránquiz e Salinas (2013), por sua vez, relatam um estudo de caso realizado com sete adolescentes imigrantes mexicanos em uma escola de ensino médio nos Estados Unidos. $\mathrm{O}$ objetivo do estudo era investigar os esforços de uma professora de Estudos Sociais em integrar os objetivos de ensino de língua in e os da sua área do conhecimento. Segundo as autoras,

\begin{abstract}
os achados mostram que a prática de pesquisa histórica por meio de fontes primárias e de questões baseadas em documentos auxiliam os estudantes no desenvolvimento de Inglês, de vocabulário acadêmico e de conceitos acadêmicos na aprendizagem de história americana (FRÁNQUIZ; SALINAS, 2013, p. 1, tradução minha ${ }^{19}$ ).
\end{abstract}

Gilliland (2014), através de uma análise do discurso etnográfica, examinou a socialização da linguagem de escritores adolescentes em uma escola estadunidense de ensino médio. Nesse estudo, a pesquisadora analisou a conversa entre professores e alunos durante encontros de orientação de escrita. Dessa maneira, em seu estudo, descreve "formas de interação que desenvolvem e formas que limitam o letramento acadêmico de alunos adolescentes multilíngues" (GILLILAND, 2014, p. 304). Essa questão do letramento acadêmico dentro das áreas do conhecimento é uma questão bem explorada na literatura. Para um estudo mais detalhado sobre o tema, é indicada a leitura do artigo de Enright (2010), que apresenta um histórico de estudos sobre letramentos acadêmicos com ênfase na aprendizagem de habilidades referentes a áreas do conhecimento dos componentes curriculares e aos aspectos linguísticos e sociais da linguagem acadêmica.

Diferentemente dos estudos relatados acima, os estudos desenvolvidos no contexto brasileiro ainda são poucos e não enfatizam estudantes de origem popular ou imigrantes e multilinguismo. O foco dos estudos está na investigação ou proposição de alternativas pedagógicas para desenvolver usos acadêmicos de leitura e escrita na escola.

Corrêa (2011) talvez tenha realizado a primeira pesquisa que considera a perspectiva de letramento acadêmico em um contexto anterior à universidade. Em seu artigo, Corrêa (2011), a partir de uma abordagem discursiva dos gêneros do discurso, traz contribuições para compreender o aspecto oculto do letramento acadêmico na escrita de estudantes préuniversitários. O autor conclui que "do ponto de vista da linguagem, é a desatenção à parte presumida do gênero que acaba levando aos chamados aspectos ocultos do letramento acadêmico" (CORRÊA, 2011, p. 355).

Nesse sentido, Silva (2016) realizou uma pesquisa-ação com alunos do oitavo ano do ensino fundamental em uma escola estadual da Bahia. A intervenção da pesquisadora teve o objetivo de envolver os estudantes em práticas de leitura e produção de gêneros acadêmicos, mais especificamente o gênero pôster científico, na disciplina de Língua Portuguesa, que foi apresentado em duas feiras de ciências da região. Para Silva (2016) incorporar o ensino de pôster científico no componente curricular de Língua Portuguesa no Ensino Fundamental tem o

\footnotetext{
objetivo de desenvolver as habilidades de observação, de desenvolvimento do pensamento crítico, de expressão oral, da leitura e escrita de outros gêneros acadêmicos (resumo, resenha, questionário de pesquisa, mapa, gráfico), que conduzirão à produção do pôster científico (p. 20).
}

Assim, o aluno pode atuar, já nessa etapa da educação, como produtor e divulgador do conhecimento produzido por ele próprio (SILVA, 2016). Como forma de levar esse

\footnotetext{
${ }^{19}$ Findings showed that the practice of historical inquiry through primary sources and document-based questions assisted students in developing English, academic vocabulary, and academic concepts in the learning of American history.
}

Revista do GELNE, Natal/RN, Vol. 21 - Número 1: p. 20-31. 2019 
conhecimento a outros contextos, Silva (2016) sugere a apresentação do pôster em mostras pedagógicas, feiras de ciências e eventos científicos.

Palacios (2016), em sua dissertação, busca refletir sobre o processo de elaboração, implementação e reelaboração de um material didático produzido para dar suporte ao ensino de metodologia científica através de práticas de letramento acadêmico na disciplina de Português, mais especificamente no primeiro ano do Ensino Médio. A motivação para realizar a pesquisa, segundo a pesquisadora, foi "uma enorme inquietação em relação ao vazio de planejamento na disciplina de Seminário Integrado e uma exigência de práticas de pesquisa que pressupunham implícitas as práticas de letramento acadêmico" (PALACIOS, 2016, p. 188). O material didático elaborado por Palacios (2016) tem o objetivo de envolver os estudantes em três etapas da pesquisas científicas, focando em gêneros acadêmicos em cada etapa: (a) planejamento, com a produção de projeto de pesquisa; (b) execução, com a produção de diário de pesquisa; (c) socialização, com a produção de pôster científico e de apresentação oral.

A tese de doutorado de Principe (2017) investigou, a partir da etnografia e do estudo de caso, a escrita de monografia em um curso técnico integrado ao médio em Automação Industrial de uma escola técnica federal. Os achados da pesquisadora apontam para conflitos de vozes em meio a relações de poder e também aspectos ocultos do letramento acadêmico durante o processo de escrita acadêmica (PRINCIPE, 2017).

Com base nessa proposta de Carvalho (2014), a pesquisadora brasileira Jéssica do Nascimento Rodrigues (2017) relata a experiência de um Projeto de Iniciação Científica Júnior realizado no Colégio Pedro II com o objetivo de desenvolver o letramento acadêmico dos estudantes do ensino médio. A autora aponta como principal contribuição dessa experiência "a certeza de que podem sim ser trazidas para a educação básica algumas práticas sociais comuns à academia" (RODRIGUES, 2017, p. 196), que, inclusive, podem fazer com que os estudantes se interessem mais pelo meio acadêmico e vejam a universidade como um horizonte possível.

De maneira geral, a pesquisa na escola parece ser o caminho em que o campo dos letramentos acadêmicos, de modo incipiente, tem se desenvolvido no âmbito da educação básica. Nesse sentido, na próxima seção discorro sobre a iniciação científica na escola como uma prática de letramento científico com potencial para o desenvolvimento inicial do letramento acadêmico dos estudantes, de modo que a escola se consolide como uma instituição de produção do conhecimento, e não apenas reprodução, conforme indica Carvalho (2014, 2015).

\section{Possibilidades para o desenvolvimento do campo no contexto brasileiro}

Conforme discutido na seção anterior, as pesquisas brasileiras têm dado ênfase à investigação e proposição do letramento acadêmico em projetos escolares. Um outro foco de pesquisa pode ser investigar e propor projetos de iniciação científica ${ }^{20}$ e de feiras de ciências ${ }^{21}$ no âmbito da educação básica.

Borges (2008) propõe que a iniciação científica seja iniciada ainda nos anos iniciais do ensino fundamental. A autora propõe que o professor discuta com os alunos suas ideias prévias sobre algum tema e proponha investigações sobre o assunto. Para Borges (2008), isso envolve "a experimentação e o estabelecimento de relações entre o que observamos e a vida cotidiana, fazendo registros sistemáticos e desenvolvendo habilidades muito importantes para a atividade científica" (p. 27). Com base em estudos piagetianos, Borges (2008) sugere que, para se chegar ao nível cognitivo de operações formais, é preciso que haja operações concretas, "sempre fazendo registros sistemáticos e organizando-os de diversas formas, com palavras e/ou desenhos, introduzindo tabelas e gráficos” (p. 30). Essas atividades de experimentações logo no início do

\footnotetext{
20 Arantes e Peres (2015) realizaram um levantamento do conjunto de programas de iniciação científica focados no ensino médio no Brasil.

${ }^{21}$ Barros e Soares (2010) apresentam um panorama das feiras nacionais e internacionais.
} 
ensino fundamental podem gerar um prazer que age em favor do desenvolvimento cognitivo dos estudantes. Por vezes a iniciação científica nas etapas da educação básica é chamada de iniciação científica júnior ou pré-iniciação científica.

As feiras de ciências historicamente têm estimulado a pesquisa na escola. As feiras, por vezes também chamadas de mostras, são entendidas como eventos em que o termo ciências deve ser percebido "no seu sentido mais amplo, referindo-se muito mais à pesquisa científica em qualquer ciência” (MANCUSO; LEITE FILHO, 2006, p. 17, grifo dos autores). Essa compreensão é importante para afastar velhas incompreensões que atribuem essas feiras apenas para a área de Ciências Naturais. Nesse sentido, Ribeiro (2015) define feira de ciências como

\begin{abstract}
um evento que reúne trabalhos de natureza científica, em geral, desenvolvidos por jovens estudantes do ensino básico, nas mais diversas áreas do conhecimento, sob a orientação de um professor responsável. Os trabalhos são expostos, pelos alunos, a visitantes e a avaliadores, com o objetivo de demonstrar o problema proposto, a importância de sua solução e como eles chegaram a ela. (p. 28)
\end{abstract}

Compreende-se as feiras também como "um processo de culminância dos trabalhos escolares realizados durante certo período letivo" (GONÇALVES, 2011, p. 207), ou seja, o resultado da realização de projetos desenvolvidos ao longo de meses de trabalho conjunto entre alunos e professores. Nesses projetos os estudantes desenvolvem práticas de linguagem envolvendo leitura e escrita que variam de acordo com a área do conhecimento de sua pesquisa. Portanto, tanto a iniciação científica como a feira de ciências parecem ser práticas sociais férteis para desenvolver os estudos de letramento acadêmico na educação básica.

$\mathrm{Na}$ concepção de Barros (2017) essas práticas de pesquisa na escola poderiam caracterizar letramento escolar e letramento científico, pois, para o autor, tais atividades seriam realizadas com o intuito de preparar os estudantes para futuras práticas valorizadas na universidade, entendida como o meio acadêmico. Por certo que as práticas de pesquisa promovidas pela iniciação científica e pelas feiras de ciências auxiliarão os alunos nas práticas de letramento privilegiadas pela universidade. No entanto, esse não é o principal objetivo dessas atividades. A pesquisa e a produção de conhecimento na educação básica promovem práticas de letramento que se justificam por si só. Inclusive já existem periódicos especializados para comunicar resultados de pesquisa realizadas na educação básica, como o Scientia Prima $^{22}$ e o InCiência ${ }^{23}$. Além disso, o movimento de feiras de ciências constituem um circuito de credenciamento de feiras escolares e locais para feiras regionais, nacionais e internacionais.

Dessa maneira, a pesquisa científica também precisa ser compreendida como um continuum, de modo que as pesquisas realizadas na educação básica sejam reconhecidas social e academicamente. Enquanto classificarmos como "superiores" ou "científicas" apenas as pesquisas realizadas no ensino superior, estaremos negando a possibilidade de participação em práticas de letramentos acadêmicos desde a educação básica. Possibilitar o contato de estudantes com a pesquisa antes da universidade, democratiza a iniciação científica desses estudantes, que, na maioria das vezes, só aconteceriam se esses estivessem ligados a grupos de pesquisa ou programas de iniciação científica no contexto universitário. Ao legitimarmos as pesquisas realizadas na escola, estamos também fortalecendo a identidade de alunos e professores como produtores do conhecimento (CARVALHO, 2014).

\title{
CONSIDERAÇÕES FINAIS
}

Neste artigo discutimos os estudos de letramentos acadêmicos como um campo de pesquisa que se desenvolveu no contexto de ensino superior, mas que, aos poucos, vem se

22 Disponível em: $<$ http://scientiaprima.incentivoaciencia.com.br/edicoes/>. Acesso em: 09 jul. 2018.

${ }^{23}$ Disponível em: < https://www.colegiodante.com.br/publicacoes/revista-inciencia/>. Acesso em: 09 jul. 2018.

Revista do GELNE, Natal/RN, Vol. 21 - Número 1: p. 20-31. 2019 
interessando pelo contexto de educação básica. Também discutimos as perspectivas de diversos autores a respeito dos letramentos acadêmicos na escola. Percebeu-se que há certa resistência em considerar que a escola possa envolver práticas acadêmicas de leitura e escrita. Há quem considere que tais práticas ocorrem apenas no ensino superior; há quem considere que essas são práticas nativas da universidade, mas que podem ser abordadas pela escola. E também há quem considere que a leitura e a escrita especializadas em cada área do conhecimento podem ser efetuadas na salas de aula de escolas como uma prática legítima. Assumindo essa perspectiva, propus que a iniciação científica e as feiras de ciências são práticas acadêmicas desenvolvidas na educação básica que podem ser objetos dos estudos de letramentos acadêmicos.

\section{REFERÊNCIAS}

ARANTES, S. L. Ferreira; PERES, S. O. Programas de iniciação científica para o ensino médio no Brasil: educação científica e inclusão social. Pesquisas e Práticas Psicossociais, São João del-Rei, v. 10, n. 1, p. 37-54, 2015.

BARTON, D.; HAMILTON, M. Local literacies: Reading and writing in one community. New York: Routledge, 1998.

BORGES, R. M. R. Iniciação científica nas séries iniciais. In: PAVÃO, A. C.; FREITAS, D. (Orgs.). Quanta ciência há no ensino de ciências. São Carlos, SP: EdUFSCAR, 2008. p. 25-34.

CARVALHO, J. A. B. Literacia académica: da escola básica ao ensino superior - uma visão integradora. Letras \& Letras, Uberlândia, v. 29, n. 2, fev. 2014.

Aula de língua e literacia académica - rupturas e interseções. Linguagem e Ensino, Pelotas, v. 18, n. 1, p. 79-97, jan./jun. 2015.

CORRÊA, M. L. G. As perspectivas etnográfica e discursiva no ensino da escrita: o exemplo de textos pré-universitários. Revista ABRALIN, v. 10, n. 4, p. 333-356, 2011.

CROSBY, C. R. The academic literacies experiences of Generation 1.5 learners: how three Generation 1.5 learners negotiated various academic literacies contexts in their first year of university study. 2007. 305 f. Tese (Doutorado em Filosofia) - College of Education and Human Ecology, Ohio State University, 2007.

ENRIGHT, K. A. Academic Literacies and Adolescent Learners: English for Subject-Matter Secondary Classrooms. TESOL Quarterly, v. 44, n. 4, p. 804-810, dez. 2010.

. Language and Literacy for a Newmainstream. American Educational Research Journal, v. 48, n. 1, p. 80-118, fev. 2011.

FIAD, R. S. A escrita na universidade. Revista ABRALIN, v. 10, n. 4, p. 357-369, 2011.

FISCHER, Adriana. A construção de letramentos na esfera acadêmica. 2007. 341 f. Tese (Doutorado em Linguística) - Programa de Pós-Graduação em Linguística, Universidade Federal de Santa Catarina, Florianópolis, 2007.

FISCHER, A.; DIONÍSIO, M. L. Perspectivas sobre letramento(s) no ensino superior: objetos de estudo em pesquisas acadêmicas. Atos de Pesquisa em Educação - PPGE/ME FURB, v. 6, n. 1, p. 79-93, jan./abr. 2011. 
FRÁNQUIZ, M.; SALINAS, C. Knowing English is Not Enough! Cultivating Academic Literacies Among High School Newcomers. The High School Journal, v. 96, n. 4, p. 339-357, abr./mai. 2013.

GILLILAND, B. Academic Language Socialization in High School Writing Conferences. The Canadian Modern Language Review, v. 70, n. 3, p. 303-330, ago. 2014.

HARKLAU, L. From high school to college: student perspectives on literacy practices. Journal of Literacy Research, v. 33, n. 1, p 33-70, 2001.

JUCHUM, M. Letramentos acadêmicos: projetos de trabalho na universidade. 2016. $171 \mathrm{f}$. Tese (Doutorado em Letras) - Programa de Pós-Graduação em Letras, Universidade Federal do Rio Grande do Sul, Porto Alegre, 2016.

LEA, M. R.; STREET, B. V. Student writing in higher education: an academic literacies approach. UK Studies in Higher Education, v. 23, n. 2, p. 157-172, 1998.

v. 45 , n. 4, p. 368-377, 2006.

. The "Academic Literacies" Model: Theory and Applications. Theory into Practice,

MARINHO, M. A escrita nas práticas de letramento acadêmico. Revista Brasileira de Linguística Aplicada, Belo Horizonte, v. 10, n. 2, p. 363-386, 2010.

MICHAEL-LUNA, S.; CANAGARAJAH, S. Multilingual Academic Literacies: Pedagogical Foundations for Code Meshing in Primary and Higher Education. Journal of Applied Linguistics and Professional Practice, v. 4, n. 1, p. 55-77, set. 2015.

NEVES, I. C. B.; SOUZA, J. V.; SCHÄFFER, N. O.; GUEDES, P. C.; KLÜSENER, R. (Orgs.) Ler e Escrever: compromisso de todas as áreas. 9 ed. Porto Alegre: Editora da UFRGS, 2011.

OLIVEIRA, G. F. Os Estudos dos Letramentos Acadêmicos no Brasil: influências, origens e perspectivas. Revista DiSsoL - Discurso, Sociedade e Linguagem, Pouso Alegre, v. 4, n. 5, p. 89-101, 2017.

OLIVER, R. Writing 'In your own Words': children's use of information sources in research projects. In: RIJLAARSDAM, G.; VAN DEN BERGH, H.; COUZIJN, M. (Orgs.). Effective Learning and Teaching of Writing: a handbook of writing in education. Amsterdam: Kluwer Academic Publishers, 2005. p. 367-380.

PALACIOS, G. G. Letramento acadêmico no ensino médio: uma experiência pedagógica a partir do material didático autoral "Manual do Jovem Pesquisador. 2016. 261 f. Dissertação (Mestrado Profissional em Ensino de Línguas) - Universidade Federal do Pampa, Bagé, 2016.

PIETRI, E. A constituição da escrita escolar em objeto de análise dos estudos lingüísticos. Trabalhos em Linguística Aplicada, Campinas, v. 46, n. 2, p. 283-297, jul./dez. 2007.

PRÍNCIPE, G. S. A escrita de monografia no ensino técnico integrado ao médio: uma prática dialógica de letramento acadêmico. 2017. 209 f. Tese (Doutorado em Linguística Aplicada) - Programa de Pós-Graduação em Linguística Aplicada, Universidade Estadual de Campinas, Campinas, 2017. 
RODRIGUES, J. N. Iniciação Científica Júnior: um caminho para o letramento acadêmico na educação básica. In: COSTA, A. V. F.; MAGALHÃES, E. M. M. (Orgs.). Percursos de iniciação científica: a prática da pesquisa nos espaços educativos. Rio de Janeiro: Autografia, 2017. p. 179-198.

RUSSELL, D. R., LEA, M.; PARKER, J.; STREET, B. DONAHUE, T. Exploring Notions of Genre in "Academic Literacies" and "Writing Across the Curriculum": Approaches Across Countries and Contexts. In: Bazerman, C.; Bonini, A. \& Figueiredo, D. (Eds.). Genre in a Changing World. Colorado: The WAC Clearinghouse, 2009. p. 395-423.

SCOLLON, R.; SCOLLON, S. B. K. Narrative, Literacy and Face in Interethnic Communication. Norwood, NJ: Ablex, 1981.

SILVA, K. C. O. Gêneros acadêmicos, letramento e interdisciplinaridade: o pôster científico no ensino fundamental II. 2016. 133 f. Dissertação (Mestrado Profissional em Letras) - Universidade Federal de Sergipe, Itabaiana, 2016.

YI, Y. Adolescent Multilingual Writer's Negotiation of Multiple Identities and Access to Academic Writing: A Case Study of a Jogi Yuhak Student in a US High School. The Canadian Modern Language Review, v. 69, n. 1, p. 207-231, mai. 2013.

Submetido em 09/11/2018

Aceito em 14/02/2019

Publicado em 07/03/2019 